\title{
THE ISPRS STUDENT CONSORTIUM: FROM LAUNCH TO TENTH ANNIVERSARY
}

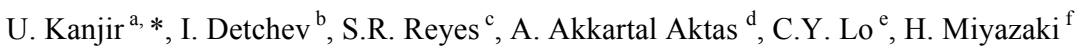

\begin{abstract}
${ }^{a}$ ZRC SAZU, Department of Remote Sensing, Novi trg 2, 1000 Ljubljana, Slovenia - ursa.kanjir@zrc-sazu.si
${ }^{\mathrm{b}}$ University of Calgary, Department of Geomatics Engineering, Calgary, AB, Canada - i.detchev@ucalgary.ca

${ }^{\mathrm{c}}$ Dept. of Geodetic Engineering, University of the Philippines Diliman, Philippines - sherylrose.reyes@gmail.com

${ }^{\mathrm{d}}$ Istanbul Technical University, 80626 Maslak Istanbul, Turkey - akkartala@itu.edu.tr

${ }^{\mathrm{e}}$ Centre for Space and Remote Sensing Research, National Central University, Taiwan - freezer@csrsr.ncu.edu.tw

${ }^{\mathrm{f}}$ University of Tokyo, Japan - heromiya@csis.u-tokyo.ac.jp
\end{abstract}

\section{Commission VI, WG VI/5}

KEY WORDS: Internet, developing countries, cooperation, information exchange, teaching, international organization, learning, planning, education

\begin{abstract}
:
The ISPRS Student Consortium is an international organization for students and young professionals in the fields of photogrammetry, remote sensing, and the geospatial information sciences. Since its start ten years ago, the number of members of the Student Consortium has been steadily growing, now reaching close to 1000. Its increased popularity, especially in recent years, is mainly due to the organization's worldwide involvement in student matters. The Student Consortium has helped organize numerous summer schools, youth forums, and student technical sessions at ISPRS sponsored conferences. In addition, the organization publishes a newsletter, and hosts several social media outlets in order to keep its global membership up-to-date on a regular basis. This paper will describe the structure of the organization, and it will give some example of its past student related activities.
\end{abstract}

\section{INTRODUCTION}

Students and young professionals at the beginning of their careers seek advice and need guidelines to address their future. Such individuals look for groups where they can find information and meet colleagues with similar interests and background as themselves. Many young people are also eager to know where they can continue or upgrade their education and develop a successful career. On the other hand, the long-term sustainability of any organization is based on the continuous integration of the new generations. Consequently, the efforts and actions aimed at attracting new fellows are a key component for the development of ISPRS (Kivilcim et al., 2012). This paper presents the main aspects of ISPRS Student Consortium and presents why integration in active international organizations is important for young individuals.

\subsection{What is the ISPRS Student Consortium?}

The ISPRS Student Consortium (SC) represents the young generation of the ISPRS society and thus its future. The student organisation was founded during the 2004 ISPRS congress in Istanbul, under the ISPRS Commission VI "Education and Outreach" and Working Group 5, "Promotion of the Profession to Students". With the implementation of the SC statutes during the 2008 ISPRS congress in Beijing, the first ISPRS Student Consortium board members were elected. Since then the Student Consortium has provided a stable link between young people from all around the world with the interest in photogrammetry, remote sensing and the geospatial information sciences. The organisation therefore works as a professional platform for the exchange of information. This exchange is achieved through organizing student specific events, publication of a newsletter, keeping an active webpage, and involvement in social media, where people share information and ideas in virtual communities/networks.

\subsection{Historical overview}

During its first year, the SC was tasked with the creation of a week-long summer school which was successfully carried out the following year in Turkey (Akkoca et al., 2006). Its success has been replicated regularly with summer schools held in a variety of locations (Kivilcim et al., 2012; Fras and Lisec, 2008). The summer schools have been arguably the SC's most widely acknowledged and popular contribution to the ISPRS. However, the SC is involved in numerous other activities including quarterly newsletter publication, email lists and a Facebook page, promotional materials, workshops, technical meetings, and social events (Kivilcim et al., 2012). The importance of the Internet has been paramount to the SC's success at keeping students engaged. Nowhere is this truer than the evolving website of the organization. Prior to 2008, the SC website consisted of a single static page. Since that time the site has expanded to include five dynamic modules: message boards, events, member profiles, materials (including the newsletter), and an image gallery (Kivilcim et al., 2010).

\subsection{Current status of the organisation}

We believe that the SC has built up a solid reputation in the last decade, considering the fact that there are only few countries around the world, which do not participate in the network. Much was accomplished based on the ideas, work and efforts of the SC board and active members. During the last ten years of existence, numerous teleconferences and video-call meetings took place between the members of the SC board and the WG $\mathrm{VI} / 5$ leaders, and with the financial help from the ISPRS

\footnotetext{
* Corresponding author.
} 
council most of the objectives were reached. The SC volunteers needed to sacrifice an extensive amount of time and effort conducting many activities in order to sustain the network.

This paper presents a full overview of the ISPRS Student Consortium and its activities during its first ten years of existence.

\section{THE STUDENT CONSORTIUM NETWORK}

\subsection{Members}

The ISPRS Student Consortium currently encompasses more than 1100 members from 93 countries from all over the world, covering mostly economically advanced countries but also many developing countries (see Figure 1). Throughout the first ten years, the number of members in the organisation has grown steadily. In the year 2012, a survey among a total number of 125 respondents was made, giving the organisation a valuable feedback from its members, in order to use them to define the key goals and objectives for the continuation and improvement of the SC. According to the survey most of the SC members got to know about the organisation through a colleague or a classmate during a conference or were informed during an ISPRS-sponsored event.

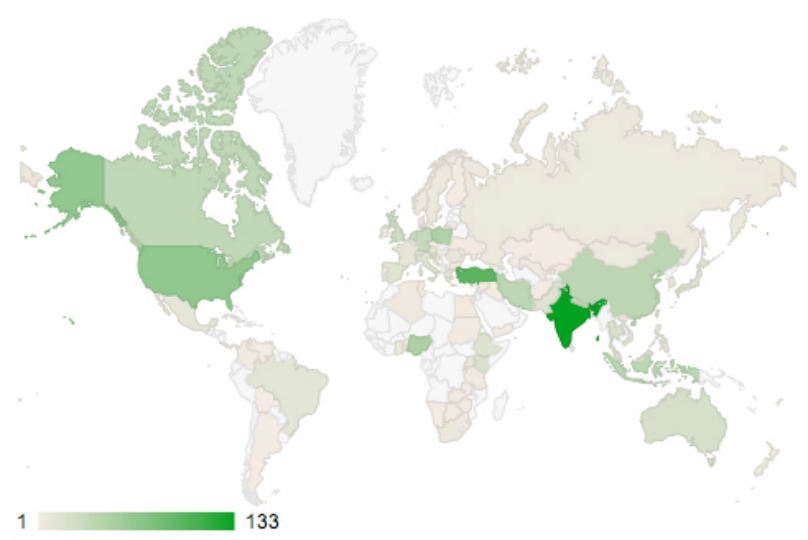

Figure 1. The Student Consortium membership in countries around the globe.

Besides technical expertise, personal connections are the corner stone of a successful professional career. As C. Heipke stated in the SC newsletter interview from November 2012: "getting to know people from around the world and making friends with them is not only a great learning experience, it provides lots of unexpected surprises and lots of fun and satisfaction".

Membership in the SC is free of charge. This way anyone can afford to join as long as they meet the eligibility criteria. All the advanced diploma students, young researchers doing their Master's or PhD studies in an ISPRS-related field can join the organisation entering some basic personal information on the webpage: http://www.isprs-sc.org. The number of members is especially increasing after summer schools, where participants connect with the SC board members in person and get informed about the organization and the team.

The ISPRS Student Consortium has also kept in touch with other sister organisations such as ASG (Asian Student Group), IGSO (International Geodetic Student Organisation), and other student organisation.

\subsection{National coordinators}

There is usually one national coordinator per country appointed by the SC board. National coordinators primarily link the SC with the educational institutions within their countries of origin. Their job is to promote the SC in their region and recruit new members. They also make suggestions and provide periodic reports of activities in their region.

\subsection{The Student Consortium board}

Once elected, the Student Consortium board members are responsible for coordinating activities in line with the scope of the organisation. They represent the organisation, communicate with the members, convene in SC meetings, help organize SC specific events, organize the content on the web site, design the newsletter, etc. Much of this work is carried out with the help of ISPRS working group WG VI/5. The Student Consortium board consist of a 'Chair', a 'Co-Chair', a 'Secretary', a 'Web responsible,' and a 'Publication responsible' personnel.

\section{STUDENT CONSORTIUM MAIN ACTIVITIES}

One of the main purposes of the Student Consortium is to provide a platform for exchange of information, to organize student-specific events and other actions that integrate students and youth more effectively into ISPRS activities either independently or within larger ISPRS events. A survey conducted in 2012 between SC members showed that most of the people asked $(62 \%)$ considered activities such as summer schools, the newsletter, youth forums, panel discussions, etc. relevant and useful for their career.

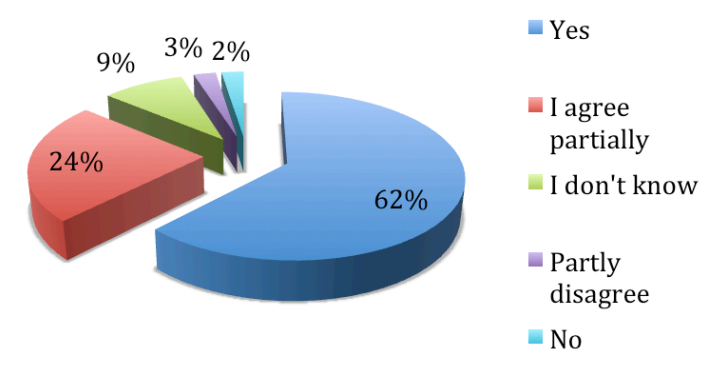

Figure 2. Do you consider SC activities relevant and/or useful for the development of your career?

All organization activities through first decade are presented and described below.

\subsection{Summer schools}

After the official establishment of the ISPRS SC in 2004, organizing and hosting summer schools across the globe has been one of the major activities of the organisation. The primary purpose of the summer schools is to provide a series of lectures and intensive trainings on the most recent technology in remote sensing and other geospatial information sciences. In addition, these summer schools provide opportunities for students and young scientist to gather, exchange information, and expand their professional networks. Moreover, the summer schools allow the participants to interact spontaneously through technical visits and social events. 
The ISPRS Student Consortium summer schools are planned in coordination with local organizers. The registration fees for the summer schools are kept at a minimum and cover lecture materials, accommodation, food, technical visits and social events. The enthusiasm of local organisers has continued the legacy of the summer schools and has appealed not only to local participants, but also to students and young researchers from other countries. Table 1 summarizes the summer schools organised by the ISPRS SC.

Table 1. Summary of the locations of SC summer schools organised from 2005 to 2013.

\begin{tabular}{|c|c|}
\hline Year & Location \\
\hline 2005 & Istanbul, Turkey \\
\hline 2007 & Ljubljana, Slovenia \\
\hline 2008 & Nanjing, China \\
\hline 2009 & Warsaw, Poland \\
\hline 2010 & Hanoi, Vietnam \\
\hline 2011 & Fayetteville, USA \\
\hline 2011 & Taoyuan, Taiwan \\
\hline 2012 & Pattaya, Thailand \\
\hline 2013 & Bali, Indonesia \\
\hline 2013 & Addis Ababa, Ethiopia \\
\hline
\end{tabular}

\section{Europe}

The first ISPRS SC summer school took place in Istanbul, Turkey in 2005. It was entitled "Satellite Data Processing and Spatio-Temporal Analysis (for Resource and Disaster Mapping, Monitoring and Management)." Considering that this was the first summer school organized by the ISPRS SC, it was well attended with participants coming from Turkey (39 local participants) and eleven other countries. It was followed by another summer school hosted by the University of Ljubljana in 2008, focusing on one of the most advanced techniques in the geospatial information sciences, which is Light Detection and Ranging (LiDAR). The number of participants who joined this event was 82 (30 local and 52 foreign). This summer school provided lessons and training on the theory and applications of LiDAR. The next summer school in Europe was organized in 2009 by the Warsaw University of Life Sciences, the oldest agricultural academic school in Poland. This marked another milestone in the history of ISPRS SC summer schools, accommodating 30 local and 57 international participants.

\section{Asia}

The first summer school in Asia was held prior to the 2008 ISPRS congress in Beijing. It was hosted by the Nanjing Normal University, with the theme, "Acquisition, Processing and Representation of 3D Geospatial Information." The succeeding summer schools were organized in coordination with the Asian Association on Remote Sensing (AARS) and the local organizers of the annual Asian Conference on Remote Sensing (ACRS). The summer schools usually take place before or after the conference.

The second ISPRS SC summer school in Asia or the first one in Southeast Asia, took place in Hanoi, Vietnam, where 27 local and 26 international students participated. The following year, the summer school was hosted by the Center for Space and Remote Sensing Research (CSRSR), a world-class remote sensing facility located in Taoyuan, Taiwan with 19 local and 29 foreign participants. In 2012, the Geo-Informatics and Space Technology Development Agency (GISTDA) of Thailand, in partnership with Burapha University, organized the $8^{\text {th }}$ summer school, introducing lectures on coastal zone monitoring and disaster management. Again, 21 local and 35 international participants joined the event. The most recent summer school took place in Bali, Indonesia, in 2013 with topics for environmental monitoring and climate change.

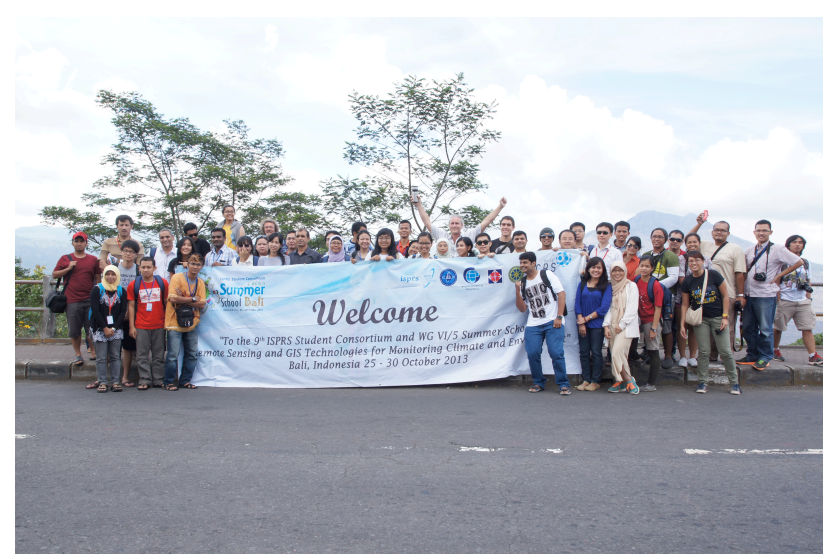

Figure 3. Participants during the field trip in the summer school held in Bali, 2013.

With the recent establishment of the Asian Association of Remote Sensing - Student Group (ASG), the student activities in Asia are expected to increase. This will occur as a result of the collaborative efforts between the two student organisations ISPRS SC and ASG.

\section{North America}

The first summer school in North America was hosted by the Fayetteville State University in 2011. The theme for this summer school was "Advanced LiDAR Processing and Applications." The number of participants who gathered for this event was 73 (53 international and 20 local). In addition to the traditional lectures, trainings, technical visits and social events, this summer school enabled the participants to interact with industry specialists like Optech Inc., Tuck Mapping Solutions Inc., Leica Geosystems Inc., Riegl USA Inc., and ESRI.

\section{Africa}

Africa is a key region for ISPRS because of the urgent need for development and the shortage of resources there (Dowman et al., 2010). The interest for ISPRS to execute its mission of promoting photogrammetry, remote sensing and the geospatial information sciences is therefore high. To enable the integration of African countries in the Student Consortium, a summer school was organized with the help of local authorities in 2013 at the UN Economic Commission for Africa (UNECA) Headquarters in Addis Ababa, Ethiopia. The majority of the participants were from six African countries, including Rwanda, Uganda, Tanzania, Ethiopia, Nigeria, and Kenya.

The summer schools, aside from gathering students and young professionals from all over the world, has successfully coordinated with a number of institutions in the field of remote sensing and the geospatial information sciences, enabling them to reach out to the younger generation. In addition, these summer schools have given the participants a unique experience through the cultural immersion and local understanding of the history and heritage of the host countries. The realization of these synergies can create more opportunities for students and young professionals in building robust international links. 


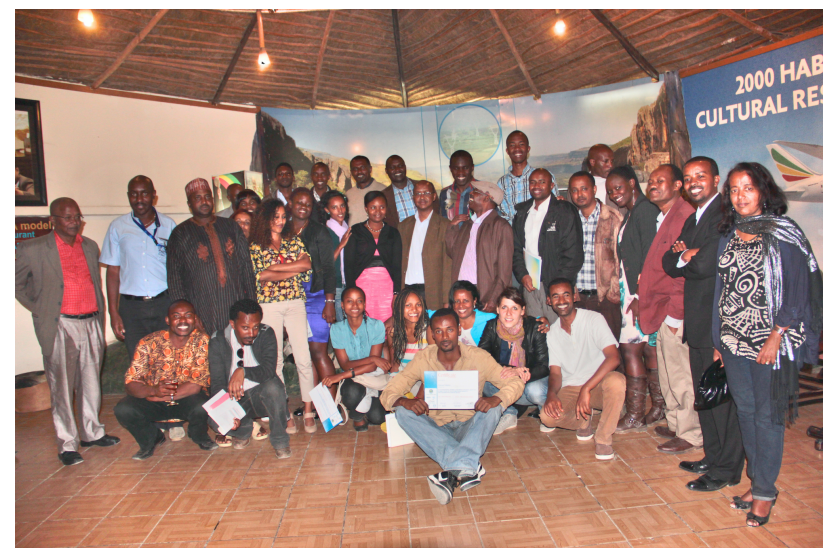

Figure 4. Participants of the first summer school held in Africa (Addis Ababa, Ethiopia) in 2013.

\subsection{Congress events}

\section{Youth forums}

Youth forums are special sessions during ISPRS-sponsored conferences (and especially the ISPRS congress) that are dedicated to students. There, young authors have the chance to publish a paper or a poster about their research and present it in front of their peers. Youth forums have been established by ISPRS since the 1990s and early 2000s, and were effectively the cradle of the SC organization. As reported by Baltsavias in 2005, the first young authors awards were given to students and young professionals during the 1996 ISPRS congress in Vienna.

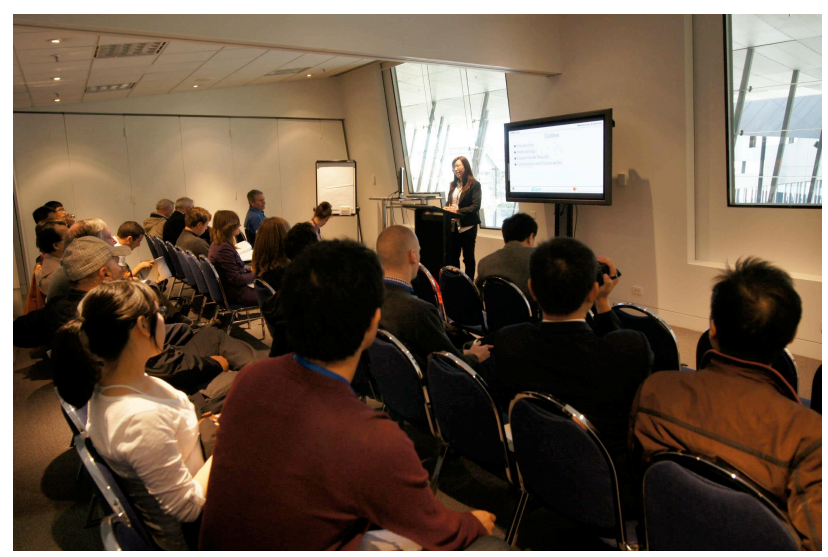

Figure 5. Youth forum presentations during the ISPRS congress in Melbourne in 2012.

\section{Panel discussion}

During the 2012 ISPRS congress in Melbourne, there was an open panel discussion held with the title "The transition period between finishing studies and getting a job". Finding the first job can be a real challenge for many students. There were three speakers (Jack Ikes from Hexagon Geosystems, Carolyn Merry from The Ohio State University, USA and Kohei Cho from Tokai University, Japan) who discussed this challenge, and presented their rich views, covering both the academic and industry perspectives of the profession. The attendees got to hear different opinions from experienced people, and fruitful interaction between the students and the invited speakers was established. The participants identified three broad skill sets that are the most sought when starting a career: academic background, personal time-management, and teamwork.

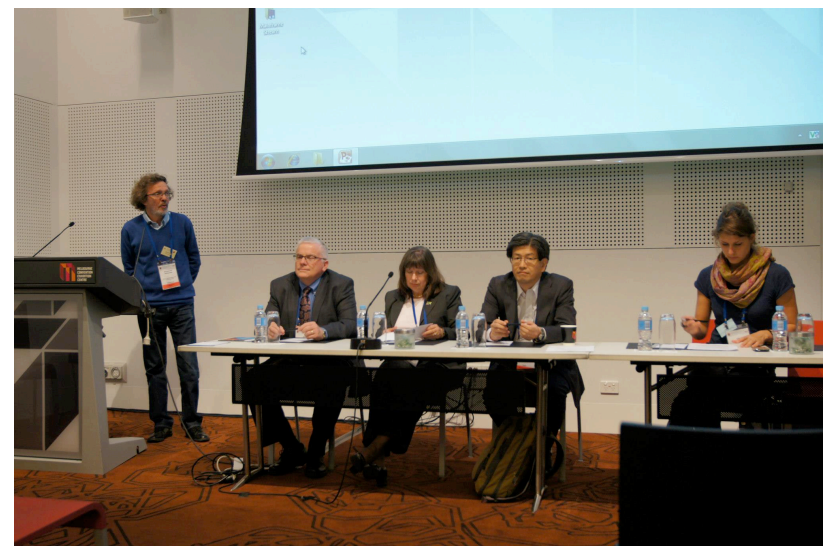

Figure 6. Invited speakers during the panel discussion (ISPRS congress in Melbourne, 2012).

\subsection{ISPRS Student Consortium newsletter}

The purpose of the SC newsletter is to inform the SC members periodically about the upcoming and past $\mathrm{SC}$ activities, to provide interesting information for students and young researchers in the fields covered by ISPRS. The newsletter is published four times a year by an international team of students and young professional volunteers starting from 2007 onwards. The newsletter is published digitally. In addition, copies of the newsletter are printed on paper once a year (with financial support mainly from the ISPRS council), and distributed at all major ISPRS events. The content of the printed edition of the newsletter is usually devoted to the theme of the SC summer school for that year, so that it is relevant to the participants. The newsletter archive, features all issues, and is available to the public on the SC's website under the "Materials" link.

Since the first issue of the newsletter, published in the autumn of 2007, the SC has published seven volumes altogether, each comprising of four issues. It is attempted that the newsletter is attractive in content and design in order to be noticed, and to create a positive image for the young readers. It consists of interviews by academics, articles from students, regular rubrics, etc. The last issue was thematic, giving space to women in science and engineering to publish their work, since photogrammetry, remote sensing, and the geospatial sciences are fields still strongly dominated by men. There was a lot of support for this special issue; therefore it was expanded into two parts.

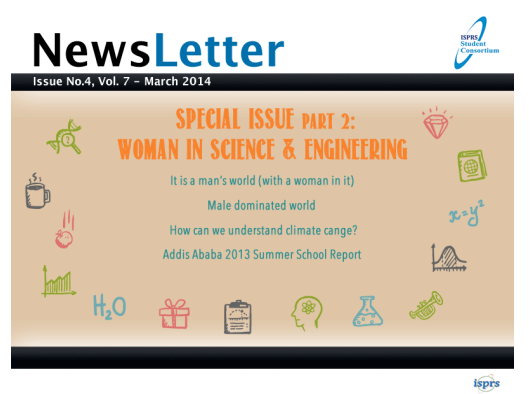

Figure 6. Cover page of the ISPRS SC newsletter Vol.7, Issue No.4 - March 2014.

The work among team members is coordinated by the editor in chief via e-mail and other social networks; hence, the publishing effort is carried out by a group of students. Each issue of the publication is made possible thanks to the involvement of 
approximately ten individuals, in addition to a number of authors of professional articles. All contributions submitted to the newsletter are published online and are under the creative commons licence. After each issue is published online, an announcement is sent via e-mail and social media so that all who follow the newsletter have the chance to read it right away.

As stated by the ex-editor in chief, Gregor Stavbar, "The SC newsletter is a great opportunity for students and young professionals to publish articles about their work and research as well as to stay informed about job and scholarship opportunities, upcoming SC related events and other interesting activities" (Kivilcim et al., 2012).

\subsection{Website}

The Student Consortium launched its official website, $\mathrm{http} / / / \mathrm{www}$.isprs-sc.org/, in 2008. Since the launch of the website, 1105 people have registered as members of the ISPRS $\mathrm{SC}$. The average number of visitors per day is 12 . The primary function of the SC web page is to convey, share and distribute information. The SC web page is not only for its members, but also for the larger world audience that is interested in the fields of photogrammetry, remote sensing, and technologies and issues related to the geospatial sciences. The main features of the website are the following:

\section{Member directory}

Every member can access information of a specific person, and can establish contact with them. This function is helpful for members to find people for hosting events such as workshops. It is also useful for members to find mentors for research activities and career development. All the personal information is secured since the system is completely developed and hosted by the SC.

\section{Event information}

The website provides up-to-date information on the ISPRS SC events (e.g., summer schools) and associated events. Members can post event information, and after review by the web administrator, the post is released to the members. This function is a useful tool for making public announcement.

\section{Document archives}

The website stores digital archives of the ISPRS SC newsletter and materials of past SC events (e.g., lectures, presentations, etc.). All material that is uploaded through the web page is available for download and is free of charge.

\subsection{Social media}

Since social media makes it easy to connect and communicate with specific groups of people, SC took the advantage of this tool as an effective way to reach may individuals. Every member can contribute content through collaborating and pursuing information about photogrammetry, GIS, remote sensing or any other geospatial studies. Anyone is free to share his or her opinion in open academic discussion, which promotes collaboration between members and offers a variety of opportunities. For example, on the SC Facebook group, members constantly exchange up-to-date information related to the profession (e.g., studies, jobs, grants, events, etc.), and they build and strengthen social relationships at the same time. The SC also manages a LinkedIn group account and a Twitter account. This evolving social influence has helped to reach more than 2,528 members with Facebook, 63 members with LikedIn, 43 followers with Twitter, as of 27 March 2014, and is increasing rapidly every day. Anyone who has interests in SC activities can join through the following pages:

- Facebook: https://www.facebook.com/groups/isprssc/

- LinkedIn: http://www.linkedin.com/groups?gid=4510838

- Twitter: http://twitter.com/ISPRS_SC

\subsection{Other involvement}

\section{Free satellite data distribution for members}

In 2013, the ISPRS SC held its first satellite imagery contest. Student Consortium members were able to send proposals for the use of satellite imagery in different applications, and had a chance to receive satellite images from the DMCii to use in their research. High quality proposals were submitted by ISPRS SC members, with a wide range of applications for DMCii imagery. After careful evaluation of all submitted proposals, there were five winners selected from around the globe (USA, Japan, Taiwan, Germany, and India). The contest winners received the requested images, but at the time of the paper preparation their results are still under development.

\section{CONCLUSIONS}

The last ten years of the ISPRS Student Consortium have been a reflection of enthusiastic collaboration between and for young people, resulting in many visible outputs. We believe that the Student Consortium plays a very important role in the global education and technology transfer, and it contributes directly and successfully to the aims of the ISPRS.

The Student Consortium is an unparalleled opportunity for young people and prospective leaders making their way into the ISPRS community. In the future, the Student Consortium should continue to work as a vibrant platform for education, research and intellectual exchange of information amongst students and young researchers - open for constructive dialogues and flow of information, with respect to the intellectual diversity of all its members.

Given that the SC is a continuously changing organisation due to the constant flux of students who later become professionals and leave the organisation, it is necessary to provide a continuous source of promotion for this organisation. We believe that people in academia or from institutions of higher learning (e.g., professors, researchers, etc.) have the most contact with students and young professionals. Our future work will therefore be to build a strong network of not only members, but also of SC supporters from academia that will promote the organisation to those who might find it interesting.

\section{ACKNOWLEDGEMENTS}

The SC board and members would like to express their deepest appreciation to all volunteers and supporters from its establishment who have always been helpful, enthusiastic and friendly. Without their support and efforts the SC could not make it to the point where it stands today.

The Student Consortium would also like to acknowledge the support of DMCii for their generous access to the free satellite data for students. 


\section{REFERENCES}

Akkoca G., Tatli, P. and Nurhan Celik, R., 2006. Organisation and Future of the ISPRS Student Consortium. In: The International Archives of the Photogrammetry, Remote Sensing and Spatial Information Sciences, Tokyo, Japan, Vol. XXXVI, Part 6, pp. 198-201.

Baltsavias, E., 2005. Student Activities within ISPRS, ISPRS Highlights, Vol. 10, No. 3, pp. 7.

Dowman, I., Kufoniyi, O., 2010. Policies for applying Earth observation in Africa: An ISPRS perspective. International Archives of the Photogrammetry, Remote Sensing and Spatial Information Sciences, Kyoto, Japan, Vol. XXXVIII, Part 8, pp. $1088-1093$.

Kivilcim, C. O., Pakdil, M. E., Sengul, A., 2010. Role of Internet as a communication platform and ISPRS Student Consortium Web Site, Proceedings of ISPRS TC VI Mid-Term Symposium, ITC, The Netherlands.

Kivilcim, C. O., Sterenczak, K., Kanjir, U., Sengul, A., Stavbar, G., Pakdil, M. E., Lobo, E., Oo, K.S., 2012, ISPRS Student Consortium: The network of youth in geoinformation society, International Archives of the Photogrammetry, Remote Sensing and Spatial Information Sciences, Vol. XXXIX-B6, XXII ISPRS Congress, 25 Aug - 01 Sept 2012, Melbourne, Australia.

Kosmatin Fras M., Lisec A., 2008. Promotion Activities of the profession to students in period $2004-2008$ and future prospects. Proceeedings of XXIst ISPRS Congress Beijing 2008. 